\title{
Nixon, Kissinger, and Allende: U.S. Involvement in the 1973 Coup in Chile \\ Lubna Z. Qureshi
}

Lanham, Lexington Books, 2009, 192 páginas, ISBN: 978-0739126554

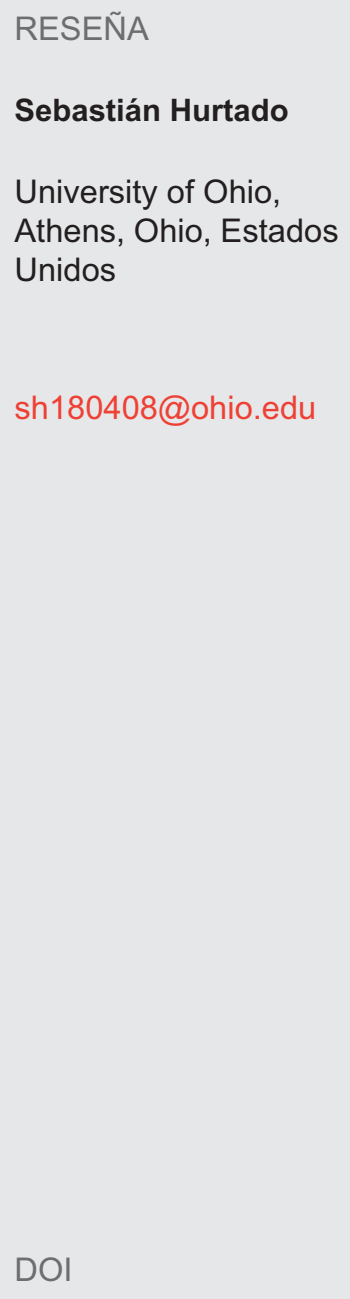

10.3232/RHI.2010. V3.N2.07
Nixon, Kissinger and Allende: U.S. Involvement in the 1973 Coup in Chile, publicado en 2009, es el resultado de la tesis doctoral de la historiadora Lubna Qureshi de la Universidad de California, Berkeley. Utilizando un marco conceptual muy cercano a la clásica interpretación marxista de la política exterior norteamericana, Qureshi sostiene que intereses económicos nacionales y privados determinaron la política del gobierno de Richard Nixon hacia Chile entre 1970 y 1973. La política de Nixon hacia América Latina, en el contexto de la cual tuvo lugar la intervención en Chile, se basó en la necesidad de Estados Unidos de obtener materias primas a bajo costo. Consideraciones ideológicas y políticas propias de la Guerra Fría ejercieron una influencia secundaria en el diseño de la política estadounidense hacia América Latina y Chile. La caída de Allende y la dictadura militar que lo sucedió fueron, según la tesis propuesta por Qureshi, consecuencia directa de la intervención norteamericana en Chile.

Qureshi basa su argumento en varios comentarios realizados por Nixon en algunas de sus conversaciones telefónicas con sus asesores y en los contactos sostenidos por el mismo Nixon, Kissinger y agentes de la ClA con representantes de grandes corporaciones estadounidenses con intereses en Chile, especialmente la ITT. Sin embargo, la evidencia provista por la autora para sostener su argumento es escasa. Aunque los contactos entre empresarios y funcionarios del gobierno estadounidense (entre ellos Kissinger y el mismo Nixon) sin duda demuestran la existencia de una relación impropia entre intereses económicos privados y el aparato estatal norteamericano, la evidencia documental presentada por Qureshi no prueba que las decisiones de Nixon y Kissinger hayan sido determinadas por dichos intereses. Por el contrario, Kissinger y la CIA rechazaron los ofrecimientos de ayuda de la ITT en las operaciones encubiertas destinadas a impedir el ascenso de Allende al poder y posteriormente a desestabilizar su gobierno. Además, muchos documentos, hoy ampliamente accesibles, muestran que la afiliación ideológica de Allende y su coalición fueron el motivo principal tras la política estadounidense hacia la Unidad Popular. La intervención estadounidense en los asuntos políticos chilenos comenzó durante la presidencia de John Kennedy y fue continuada con 
gran celo por la administración de Lyndon B. Johnson. Si bien Qureshi no discute en profundidad este punto, su exclusiva dedicación al gobierno de Nixon y su énfasis en motivaciones económicas oscurecen las continuidades en la política estadounidense hacia Chile y la relevancia de la atmósfera de la Guerra Fría en las decisiones tomadas por el ejecutivo norteamericano entre 1963 y 1973.

Además de la debilidad de su argumento sobre la política exterior norteamericana, Nixon, Kissinger and Allende presenta otro problema metodológico e intelectual relevante. Qureshi sostiene que la intervención estadounidense fue la principal causa de la polarización política en Chile y de la caída de la Unidad Popular. Por supuesto, es indudable que la política hostil de Nixon contribuyó enormemente a incubar la situación de polarización y violencia política que se adueñó de Chile durante el gobierno de Allende. Sin embargo, la idea de que la intervención de Estados Unidos fue la causa fundamental, tanto de la crisis política de los años de la Unidad Popular, como de su violenta resolución a través del golpe militar, supone que los actores chilenos jugaron papeles secundarios en el desarrollo y el desenlace de esta historia. Esta tesis podría tener un peso intelectual importante si se fundara en un estudio sistemático de la realidad chilena de aquellos años y de los efectos que en ella tuvo la política exterior estadounidense. Lamentablemente, Qureshi consultó muy pocos libros escritos por autores chilenos y sólo uno en español. Además, aunque su bibliografía indica que revisó documentos en el Archivo Histórico del Ministerio de Relaciones Exteriores, el aparato crítico de Nixon, Kissinger and Allende denota la ausencia casi absoluta de fuentes primarias chilenas en la elaboración del texto. Prácticamente todo el contexto histórico del relato de Qureshi se basa en un puñado de libros sobre Chile, todos en inglés y muchos de los cuales tampoco se basan en revisión de fuentes primarias chilenas. En otras palabras, el material revisado por Qureshi es útil para un estudio de la política exterior de la administración Nixon-y la autora debe ser elogiada por la utilización de fuentes no exploradas en profundidad previamente-pero no permite un análisis serio de sus consecuencias en Chile.

Qureshi dedica considerable espacio a describir la situación interna de Chile durante el gobierno de Allende. Algunos de sus comentarios denotan un conocimiento sólo superficial de algunos aspectos de la historia contemporánea del país. En su descripción de la insubordinación militar de 1969 conocida como Tacnazo, por ejemplo, Qureshi no menciona que la rebelión fue una protesta gremial más que un intento de golpe de estado (p. 39). Asumiendo esto último, Qureshi señala que el Tacnazo fue una advertencia para los futuros gobernantes de Chile de que cualquier tipo de reforma sería posible sólo en la medida que los militares lo permitieran. Si bien esta narrativa parece lógica en retrospectiva, resulta cuestionable en vista del hecho de que la única agrupación política que no condenó la breve insurrección de 1969 fue el Partido Socialista. Más adelante, Qureshi sostiene que el MIR no abandonó su compromiso con la vía armada porque, de algún modo, comprendía que la represión que se desataría tras la caída de Allende sería brutal (p. 122). Dado que la discusión de este punto es más bien general, al lector desinformado le quedará la impresión de que el MIR optó por un discurso extremista por razones defensivas y no por su compromiso con una postura ideológica intransigente. 
Qureshi considera que la intervención del gobierno de Nixon en los asuntos políticos chilenos fue una clara manifestación del imperialismo norteamericano. Tal afirmación es discutible, mas no está lejos de la realidad de las relaciones entre Chile y Estados Unidos en los años 60 y 70. Sin embargo, la metodología de Qureshi deja poco espacio para desafiar tal noción. Tanto sus fuentes primarias como la abrumadora mayoría de sus fuentes secundarias son de origen norteamericano. Por esta razón, no es sorprendente que los efectos de la política exterior estadounidense parezcan determinantes en el curso de la historia de Chile durante el periodo en cuestión. En Nixon, Kissinger and Allende, los actores chilenos y sus visiones de la situación del país juegan un papel secundario. Irónicamente, la propuesta metodológica de Qureshi contribuye a perpetuar, esta vez en el mundo de la academia, el paradigma histórico del imperialismo norteamericano tan vehementemente criticado por ella. 